\title{
FeedER: a feedback-regulated enzyme-based slow-release system for fed-batch cultivation in microtiter plates
}

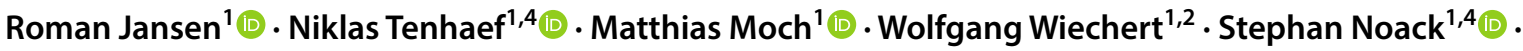 \\ Marco Oldiges ${ }^{1,3}$
}

Received: 10 March 2019 / Accepted: 23 July 2019 / Published online: 9 August 2019

(c) The Author(s) 2019

\begin{abstract}
With the advent of modern genetic engineering methods, microcultivation systems have become increasingly important tools for accelerated strain phenotyping and bioprocess engineering. While these systems offer sophisticated capabilities to screen batch processes, they lack the ability to realize fed-batch processes, which are used more frequently in industrial bioprocessing. In this study, a novel approach to realize a feedback-regulated enzyme-based slow-release system (FeedER), allowing exponential fed-batch for microscale cultivations, was realized by extending our existing Mini Pilot Plant technology with a customized process control system. By continuously comparing the experimental growth rates with predefined set points, the automated dosage of Amyloglucosidase enzyme for the cleavage of dextrin polymers into D-glucose monomers is triggered. As a prerequisite for stable fed-batch operation, a constant $\mathrm{pH}$ is maintained by automated addition of ammonium hydroxide. We show the successful application of FeedER to study fed-batch growth of different industrial model organisms including Corynebacterium glutamicum, Pichia pastoris, and Escherichia coli. Moreover, the comparative analysis of a C. glutamicum GFP producer strain, cultivated under microscale batch and fed-batch conditions, revealed two times higher product yields under slow growing fed-batch operation. In summary, FeedER enables to run 48 parallel fed-batch experiments in an automated and miniaturized manner, and thereby accelerates industrial bioprocess development at the screening stage.
\end{abstract}

Keywords FeedER $\cdot$ Exponential fed-batch $\cdot$ Miniaturized cultivation $\cdot$ C. glutamicum $\cdot$ High-throughput bioprocess development $\cdot$ Online monitoring

Roman Jansen and Niklas Tenhaef authors contributed equally to this work.

Electronic supplementary material The online version of this article (https://doi.org/10.1007/s00449-019-02180-z) contains supplementary material, which is available to authorized users.

Marco Oldiges

m.oldiges@fz-juelich.de

1 Forschungszentrum Jülich, Institute of Bioand Geosciences, Biotechnology (IBG-1), Jülich, Germany

2 RWTH Aachen University, Computational Systems Biotechnology (AVT.CSB), Aachen, Germany

3 Institute of Biotechnology, RWTH Aachen University, Aachen, Germany

4 Bioeconomy Science Center (BioSC), Forschungszentrum Jülich GmbH, Jülich, Germany

\section{Introduction}

The last decade is marked by tremendous advances in the development of highly engineered strains for bioprocess application. Through the emergence of specific gene editing tools in combination with high-throughput screening tools such as biosensors, large strain libraries can be generated within a short period of time [1-3]. To determine the best candidates for process development, these libraries need to be characterized in detail, and thus the number of necessary experiments can easily sum up to a thousand per library [4]. Consequently, there is a great demand for systems allowing an increased experimental throughput without sacrificing data accuracy and reproducibility.

Various stand-alone microbioreactor (MBR) systems have evolved in the last years, allowing strain phenotyping with an adequate throughput without loss of control and monitoring capabilities [5]. To further increase phenotyping capacity and decrease manual handling steps, these MBR systems 
are often embedded into robotic platforms. The parallelized cultivation in combination with a liquid handling system allows the full pipeline from automated inoculation, dosing, and sampling procedures followed by analytics [6].

The current bottleneck of these platforms is the mode of cultivation, i.e., they are mostly restricted to batch operation. However, fed-batch operation is preferred in industrial production to prevent, e.g., oxygen limitation, substrate inhibition, and overflow metabolism [7], and to achieve higher product titers and yields. Screening in batch mode might also lead to wrong strain selections due to artificial environmental conditions [8]. Consequently, multiple approaches to also enable fed-batch cultivation on the available MBR platforms have been developed.

For example, in combination with a liquid handling system, a dissolved oxygen (DO)-triggered fed-batch can be realized. Every time the DO signal spikes, indicating the complete consumption of all carbon sources, new substrate can be added via the robot [9]. However, this creates an oscillating effect on the cell metabolism, and thus the obtained results are not fully comparable to bioreactor fedbatch cultivations.

Alternatively, diffusion-based fed-batch operation can be achieved through the addition of silicone elastomer discs containing the primary substrate $[8,10]$. As an extension, specialized MTPs with hydrogel channels connected to a substrate reservoir can be applied for a diffusion-based release [11]. On the other hand, enzymatic release of D-glucose from a carbohydrate polymer allows MBR fed-batch cultivation, which is limited to a low release rate without $\mathrm{pH}$ control. However, through variation of enzyme concentration, the release rate can be changed [12-14]. Mixed substrate feeding might be beneficial when working with organisms such as Pichia pastoris to avoid substrate inhibition [15]. A major disadvantage of all these technologies is the lack of control for the substrate release rate during a fed-batch process. An automated process with addition of enzyme, carbohydrate polymer as well as free D-glucose has been established for online experimental redesign, and thus parameter estimation [16]. Although this process can be used for parameter estimation of a known model, it might be unsuitable for accelerated phenotyping experiments, e.g., due to a lack of valid bioprocess models.

Microfluidic MBR systems utilizing microchannels and microvalves for substrate feeding are another promising alternative [17-19]. However, these systems are still technically challenging. A parallel investigation toward the necessity of $\mathrm{pH}$ control in MTPs was conducted, however, without full automation and with no application of any fed-batch strategies [20].

In this study, we present an advanced approach for the utilization of slow-release systems to achieve exponential growth rates during fed-batch microscale cultivation.
In particular, the substrate release rate and, therefore, the growth rate is feedback controlled based on online biomass measurements and automated $\mathrm{pH}$ control. We show the general applicability of our microscale fed-batch approach using the model organisms, Corynebacterium glutamicum, Pichia pastoris, and Escherichia coli. Additionally, we studied the impact of different growth rates on the formation of the model product GFP with $C$. glutamicum.

\section{Materials and methods}

\section{Chemicals}

All chemicals (analytical grade) were purchased from Carl Roth (Karlsruhe, Germany) or Sigma-Aldrich (Steinheim, Germany).

\section{Bacterial strains and medium}

Corynebacterium glutamicum strain ATCC 13032 was used. The strain expresses and secretes a GFP-fusion protein pCGPhoD ${ }^{\mathrm{Cg}}$-GFP under the control of an IPTG-inducible promoter of the pEKEx 2 plasmid with kanamycin resistance [21]. The PhoD signal peptide allows for fully folded GFP secretion utilizing the Tat-pathway. Kanamycin was added at a concentration of $25 \mathrm{mg} \mathrm{L}^{-1}$. The strain was stored at $-80{ }^{\circ} \mathrm{C}$ via cryo-conservation. A defined CGXII medium [22] was slightly adapted and used for cultivation. The medium contained per liter of deionized water: $1 \mathrm{~g} \mathrm{~K}_{2} \mathrm{HPO}_{4}$, $1 \mathrm{~g} \mathrm{KH}_{2} \mathrm{PO}_{4}, 13.25 \mathrm{mg} \mathrm{CaCl}{ }_{2} * 2 \mathrm{H}_{2} 0,0.25 \mathrm{~g} \mathrm{MgSO}_{4}$ * $7 \mathrm{H}_{2} \mathrm{O}, 10 \mathrm{mg} \mathrm{FeSO}_{4} * 7 \mathrm{H}_{2} 0,10 \mathrm{mg} \mathrm{MnSO}_{4} * 4 \mathrm{H}_{2} \mathrm{O}$, $0.313 \mathrm{mg} \mathrm{CuSO}{ }_{4} * 5 \mathrm{H}_{2} 0,0.02 \mathrm{mg} \mathrm{NiCl}{ }_{2} * 6 \mathrm{H}_{2} \mathrm{O}, 1 \mathrm{mg}$ $\mathrm{ZnSO}_{4} * 7 \mathrm{H}_{2} \mathrm{O}, 0.2 \mathrm{mg}$ biotin, $30 \mathrm{mg}$ protocatechuic acid,

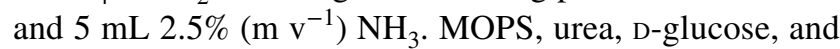
dextrin from potato starch (Sigma-Aldrich, Steinheim, Germany) were added in varying concentrations for each experiment. The components were prepared as stocks, sterilized separately, and added immediately before the cultivation. The vitamin and protocatechuic acid stocks were aliquoted and stored at $-20{ }^{\circ} \mathrm{C}$ to ensure identical conditions for each experiment. For slow-release cultivations, a $300 \mathrm{U} \mathrm{L}^{-1}$ stock of Amyloglucosidase from A. niger (Sigma-Aldrich, Steinheim, Germany) was stored at $4{ }^{\circ} \mathrm{C}$ on the robotic workspace and added as needed by the liquid handling system to the cultivation.

E. coli K12 MG1655 wild-type strain was cultivated in slightly modified Wilms-MOPS medium [23]. The medium contained per liter of deionized water: $5 \mathrm{~g}\left(\mathrm{NH}_{4}\right)_{2} \mathrm{SO}_{4}, 0.5 \mathrm{~g}$ $\mathrm{NH}_{4} \mathrm{Cl}, 3 \mathrm{~g} \mathrm{~K}_{2} \mathrm{HPO}_{4}, 2 \mathrm{~g} \mathrm{Na}_{2} \mathrm{SO}_{4}, 0.5 \mathrm{~g} \mathrm{MgSO}_{4} * 7 \mathrm{H}_{2} \mathrm{O}$, $10.46 \mathrm{~g}$ MOPS, $0.01 \mathrm{~g}$ thiamine hydrochloride, $0.54 \mathrm{mg}$ $\mathrm{ZnSO}_{4} * 7 \mathrm{H}_{2} \mathrm{O}, 0.48 \mathrm{mg} \mathrm{CuSO}{ }_{4} * 5 \mathrm{H}_{2} \mathrm{O}, 0.3 \mathrm{mg} \mathrm{M \textrm {SO } _ { 4 }}$ * $\mathrm{H}_{2} \mathrm{O}, 0.54 \mathrm{mg} \mathrm{CoCl}{ }_{2} * 6 \mathrm{H}_{2} \mathrm{O}, 41.76 \mathrm{mg} \mathrm{FeCl}_{3} * 6 \mathrm{H}_{2} \mathrm{O}$, 
$1.98 \mathrm{mg} \mathrm{CaCl}{ }_{2} * 2 \mathrm{H}_{2} \mathrm{O}$, and $33.39 \mathrm{mg} \mathrm{Na} 2$ EDTA. $35 \mathrm{~g}$ dextrin and $5 \mathrm{D}$-glucose were added as the sole carbon sources. The components were prepared as stocks, sterilized separately, and added immediately before the cultivation. For the cultivation of $P$. pastoris $\mathrm{X} 33$, a different chemically defined medium was slightly adapted and utilized [24]. The medium contained per liter of deionized water: $7.5 \mathrm{~g}\left(\mathrm{NH}_{4}\right)_{2} \mathrm{SO}_{4}$, $1 \mathrm{~g} \mathrm{MgSO}_{4} * 7 \mathrm{H}_{2} \mathrm{O}, 8.5 \mathrm{~g} \mathrm{KH}_{2} \mathrm{PO}_{4}, 0.05 \mathrm{mg}$ biotin, $1 \mathrm{mg} \mathrm{Ca}$ D-panthothenate, $1 \mathrm{mg}$ nicotinic acid, $25 \mathrm{mg}$ myo-inositol, $1 \mathrm{mg}$ thiamin hydrochloride, $1 \mathrm{mg}$ pyridoxol hydrochloride, $0.2 \mathrm{mg}$ p-amino benzoic acid, $30 \mathrm{mg} \mathrm{Na} 2$ EDTA, $9 \mathrm{mg}$ $\mathrm{ZnSO}_{4} * 7 \mathrm{H}_{2} \mathrm{O}, 1.55 \mathrm{mg} \mathrm{MnCl}{ }_{2} * 6 \mathrm{H}_{2} \mathrm{O}, 0.6 \mathrm{mg} \mathrm{CuSO}_{4} *$ $5 \mathrm{H}_{2} \mathrm{O}, 0.8 \mathrm{mg} \mathrm{Na} \mathrm{MoO}_{4} * \mathrm{H}_{2} \mathrm{O}, 9 \mathrm{mg} \mathrm{CaCl} * 2 \mathrm{H}_{2} \mathrm{O}, 6 \mathrm{mg}$ $\mathrm{FeCl}_{2} * 7 \mathrm{H}_{2} \mathrm{O}, 2 \mathrm{mg} \mathrm{H}_{3} \mathrm{BO}_{3}, 0.2 \mathrm{mg} \mathrm{KI}$, and $10.46 \mathrm{~g}$ MOPS. $35 \mathrm{~g}$ Dextrin and $5 \mathrm{D}$-glucose were added as the sole carbon sources. The components were prepared as stocks, sterilized separately and added immediately before the cultivation.

\section{Microbioreactor cultivation}

Cultivations were performed utilizing BioLector devices (m2p-labs GmbH, Baesweiler, Germany). FlowerPlates as characterized by Funke et al. [25], commercialized by $\mathrm{m} 2 \mathrm{p}-$ labs (MTP-48-BO), and sealed with a sealing foil for automation (F-GPRS48-10) (all by m2p-labs GmbH, Baesweiler, Germany) were used. The medium was inoculated directly from a frozen cryo-culture to an $\mathrm{OD}_{600}$ of 0.1 . The cultivation was performed at $1300 \mathrm{rpm}$ with an orbital shaking diameter of $3 \mathrm{~mm}$, the humidity set above $85 \%$, and an initial filling volume of $800 \mu \mathrm{L}$. The biomass, dissolved oxygen, and $\mathrm{pH}$ were measured non-invasively throughout the cultivation. The BioLector is integrated into a liquid handling system (EVO 200) provided by Tecan (Männedorf, Switzerland) with eight steel needle tips, allowing for automated dosing and sampling into each well of the microtiter plate.

\section{Process control system}

To realize the feedback-regulated slow-release fed-batch system, a tailor-made, python-based process control system was employed. The program reads and processes BioLector data during the experiment. The current growth rate for each cultivation is determined by performing a spline approximation of the blanked backscatter data points obtained from the last $30 \mathrm{~min}$. The first derivative of the resulting spline is evaluated at the input time points. The resulting vector is then divided by the blanked backscatter data points. The average of this vector serves as an estimation for the current growth rate.

Based on that rate, the decision to add enzyme is made. At first, end of the initial batch is detected (growth rate $<0.05$ $\mathrm{h}^{-1}$ ). This triggers the addition of the initial dose of enzyme. After starting the fed-batch, the following procedure is done: if the growth rate falls under a set threshold, the enzyme is added to the cultivation using the liquid handling system. The amount of added enzyme is determined by multiplication of the current backscatter value with a factor to compensate necessary increase of release rate at higher biomass concentration. For $\mathrm{pH}$ control, the measured $\mathrm{pH}$ is monitored. If the $\mathrm{pH}$ drops below 7.1, $10 \mu \mathrm{L}$ of $2.5 \%\left(\mathrm{w} \mathrm{v}^{-1}\right) \mathrm{NH}_{3}$ is added using the liquid handling system. In addition to controlling the process, the program also provides the user with plots of the relevant data during the process.

\section{Product analysis}

The secreted GFP was analyzed via optical measurements performed by the BioLector with LED/filter module for fluorescence measurement.

\section{Results and discussion}

\section{Automated pH control for microtiter plate cultivation}

The slow-release system used in this study is based on the conversion of a dextrin polymer to D-glucose by the enzyme Amyloglucosidase from Aspergillus niger. To establish feedback-controlled enzyme release-based fed-batch cultivations, it is essential that the D-glucose release rate is only dependent on the enzyme activity modulated by the amount of enzyme in the cultivation media. However, the activity of Amyloglucosidase is strongly dependent on the $\mathrm{pH}$. For example, it was shown by Toeroek et al. that the activity increased by $40 \%$ when the $\mathrm{pH}$ was changed from 7.3 to 6.8 [26]. Therefore, for a controllable enzymatic release rate of $\mathrm{D}$-glucose, a constant $\mathrm{pH}$ is an essential prerequisite. This constant $\mathrm{pH}$ may be provided by the standard defined medium for C. glutamicum, CGXII [22], which contains $200 \mathrm{mM}$ MOPS as buffer system. A different strategy is based on an automated, one-sided $\mathrm{pH}$ control using the capabilities of a liquid handling system. We compared both strategies by performing eight replicate cultivations of C. glutamicum wild-type under three different conditions (Fig. 1).

As a reference (condition A), CGXII medium with $83.25 \mathrm{mM}$ urea and $200 \mathrm{mM}$ MOPS was used and no external pH control was applied. In condition B, CGXII medium without urea was tested, again without external $\mathrm{pH}$ control. For automated $\mathrm{pH}$ control (condition $\mathrm{C}$ ), we modified the CGXII medium to implement a control strategy as follows: first, to enable a one-sided control strategy, no urea was added. Second, to achieve a more sensitive response, the buffer capacity was reduced to $50 \mathrm{mM}$ MOPS, also lowering osmotic pressure. Third, when the online-measured $\mathrm{pH}$ 

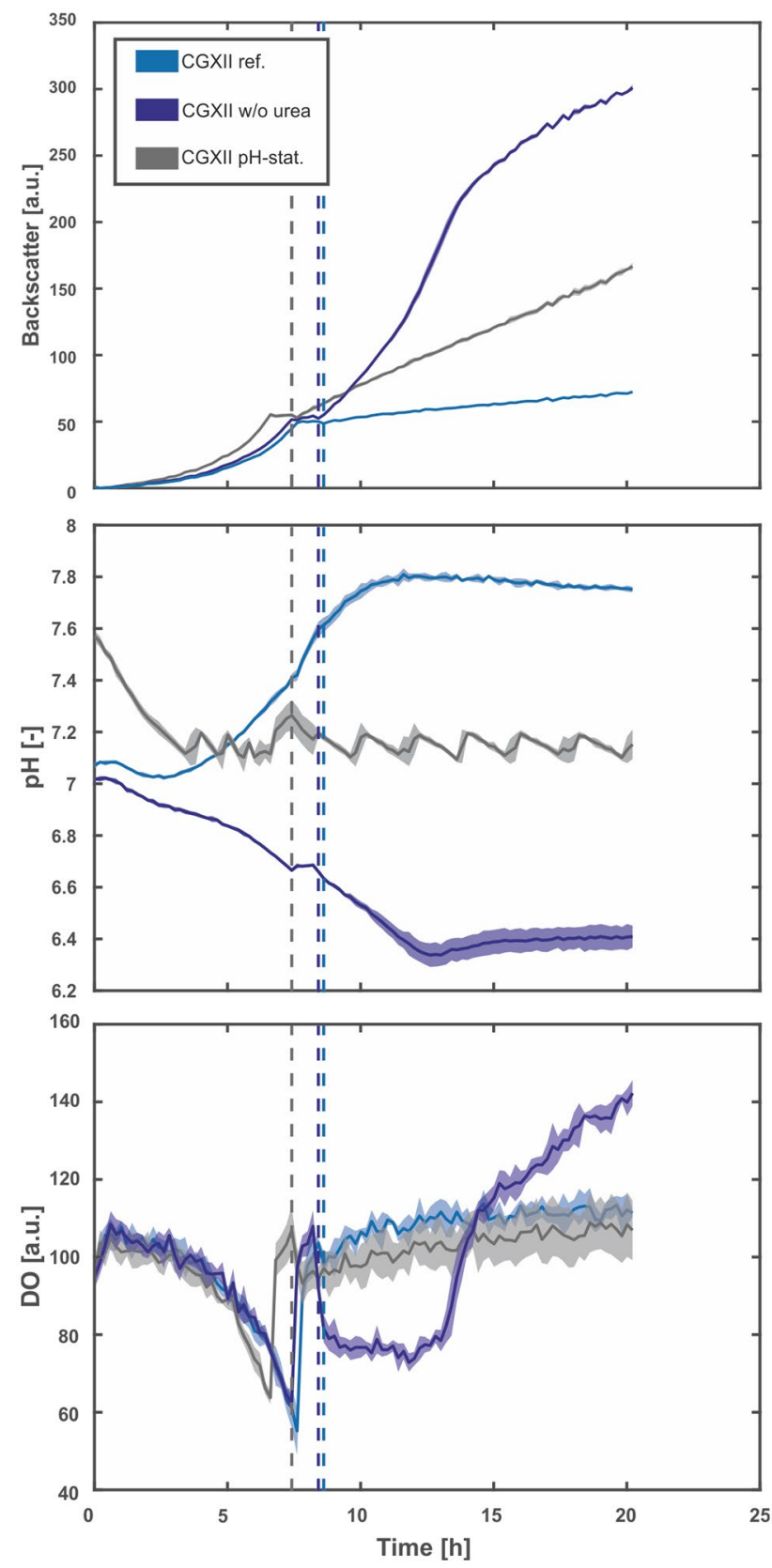

Fig. 1 Implementation of a $\mathrm{pH}$ control for microscale fed-batch cultivation. Cultivations were performed in a 48-well FlowerPlate under standard conditions with $5 \mathrm{~g} \mathrm{~L}^{-1} \mathrm{D}$-glucose and $35 \mathrm{~g} \mathrm{~L}^{-1}$ dextrin as the carbon sources. Solid lines represent the arithmetic means of six biological replicates and shaded areas represent the corresponding standard deviations. The light blue lines show measurements of the cultivation in CGXII medium with $5 \mathrm{~g} \mathrm{~L}^{-1}$ urea and $200 \mathrm{mM}$ MOPS, but without any $\mathrm{pH}$ control (condition A). The dark blue lines show the measurements for condition $\mathrm{B}$, where CGXII medium without urea was used. The grey lines show condition $\mathrm{C}$ : cultivation without urea, only $50 \mathrm{mM}$ MOPS and automated $\mathrm{pH}$ control. A threshold for the $\mathrm{pH}$ was set at 7.1. When the online signal dropped below the set point, $10 \mu \mathrm{L}$ of $2.5 \%\left(\mathrm{~m} \mathrm{v}^{-1}\right) \mathrm{NH}_{3}$ was added to the cultivation by the liquid handling system. The dotted lines indicate the time points when the enzyme was pulsed into the media (color figure online) drops below a set point of 7.1, $10 \mu \mathrm{L}$ of $2.5 \%\left(\mathrm{~m} \mathrm{v}^{-1}\right) \mathrm{NH}_{3}$ was added by the liquid handling system.

For all conditions, $5 \mathrm{~g} \mathrm{~L}^{-1}$ D-glucose was added to the medium for an initial batch phase. For the fed-batch phase, $35 \mathrm{~g} \mathrm{~L}^{-1}$ dextrin was added, which was then converted to D-glucose monomers through addition of Amyloglucosidase. The end of the initial batch phase was detected automatically via at-line analysis of the growth rate. Subsequently, an initial single pulse of Amyloglucosidase was automatically added into each well to start the fed-batch phase (represented as dotted lines in Fig. 1).

For cultivations in condition A, the $\mathrm{pH}$ strongly increased from 7.1 to 7.8 due to the assimilation and degradation of urea in the initial batch phase. Even in the higher buffered condition with $200 \mathrm{mM}$ MOPS, this effect could not be prevented. At this $\mathrm{pH}$, the activity of the D-glucose-releasing enzyme is very low. Consequently, only a slight increase in backscatter was observed in the fed-batch phase.

On the contrary, for condition B, where no urea was added to the medium, the $\mathrm{pH}$ decreased throughout the initial batch phase from 7.0 to 6.7 due to ammonium uptake. After addition of the enzyme, the backscatter signal increased rapidly as expected, indicating fast biomass growth caused by release of D-glucose. However, the $\mathrm{pH}$ continued to decrease during fed-batch phase, which in turn further increased the activity of the enzyme. As a result, the growth curve did not follow the intended linear trend, but accelerated in a rather unpredictable manner. The $\mathrm{pH}$ drop seems to be a consequence of slight acidification which goes along with the utilization of D-glucose and is again not fully compensated by the buffered condition. This renders our approach for controlled exponential fed-batch cultivation impossible.

In condition $\mathrm{C}$, the automated $\mathrm{pH}$-control for the modified CGXII medium worked as expected. Throughout the cultivation, the control strategy kept the $\mathrm{pH}$ between 7.1 and 7.3. After the initial batch phase and addition of Amyloglucosidase, a linear increase of backscatter was observed, indicating that the D-glucose release rate was indeed kept constant by maintaining a constant $\mathrm{pH}$. The small oscillation of $\mathrm{pH}$ does not seem to hamper achieving a linear growth profile. With this setup at hand, development of an exponential fedbatch system was started.

\section{Feedback-regulated enzyme-based slow-release fed-batch cultivation (FeedER)}

FeedER is built on the ability to calculate the current growth rate during cultivation. This is done by utilizing the noninvasive biomass measurement via backscatter and appropriate processing of the signal via spline approximation as described previously [27].

A drop in the current growth rate below a predefined threshold triggers the addition of Amyloglucosidase. By 
Fig. 2 Exponential fed-batch culture of C. glutamicum ATCC 13032 with enzyme addition at a growth rate threshold of $\mu_{\text {set }}=0.1 \mathrm{~h}^{-1}$. Cultivations were performed in a 48 -well FlowerPlate at $30{ }^{\circ} \mathrm{C}$, $1300 \mathrm{rpm},>85 \%$ humidity, and the initial filling volume was $800 \mu \mathrm{L}$. Modified CGXII medium with $5 \mathrm{gL}^{-1}$ D-glucose, a dextrin equivalent of $75 \mathrm{~g} \mathrm{~L}^{-1}$ D-glucose and $50 \mathrm{mM}$ MOPS were used. The $\mathrm{pH}$ was kept constant at 7.1 through addition of $2.5 \%\left(\mathrm{~m} \mathrm{v}^{-1}\right) \mathrm{NH}_{3}$. The growth rate was kept above the set point through specific addition of Amyloglucosidase. Dark lines represent the arithmetic means of 12 biological replicates and shaded areas represent the corresponding standard deviations

adding this enzyme, the overall D-glucose release rate is increased. The amount of enzyme to be added is dependent on the current biomass concentration and, therefore, has to be accordingly increased along the cultivation. The initial dosing volume was $5 \mu \mathrm{L}$ and reached up to $25 \mu \mathrm{L}$ per dose. To account for the changing volume due to the addition of enzyme and base, the backscatter signal is volume corrected.

We tested this strategy by cultivation of $C$. glutamicum ATCC 13032 in modified CGXII medium as described in Sect. 3.1. As a first set point for the growth rate $\left(\mu_{\text {set }}\right)$ triggering enzyme addition, we applied $\mu_{\text {set }}=0.1 \mathrm{~h}^{-1}$ (Fig. 2). After an initial batch phase on $5 \mathrm{~g} \mathrm{~L}^{-1} \mathrm{D}$-glucose, the fed-batch cultivation was started through addition of the first dose of Amyloglucosidase. During the fed-batch, further enzyme was added, if the growth rate dropped below the threshold as described above. The $\mathrm{pH}$ was kept constant between 7.1 and 7.3 through the addition of $2.5 \%\left(\mathrm{~m} \mathrm{v}^{-1}\right) \mathrm{NH}_{3}$. The fed-batch cultivation was stopped when the particular well reached a maximal filling volume of $1200 \mu \mathrm{L}$. An exemplary dosing history can be found in Fig. S3.

The novel strategy allows for a highly reproducible fedbatch cultivation, as demonstrated by the small standard deviations for all signals (cmp. shaded areas in Fig. 2). The average experimental growth rate for 12 biological replicates during the fed-batch phase was $\mu_{\exp }=0.14 \pm 0.01 \mathrm{~h}^{-1}$. The resulting deviation from the set point can be explained by the implemented dosing procedure. Each time the measured growth rate drops below the threshold, new enzyme was added to increase the growth rate accordingly. A posteriori calculation of the growth rate during the fed-batch phase, therefore, yields a value higher than the threshold defined. The increase of $\mathrm{pH}$ after $25 \mathrm{~h}$ might be due to metabolization of small amounts of acidic by-products after depletion of the main carbon source D-glucose. This is consistent with a steady DO signal, which took until all carbon was depleted and the DO signal rises again.

We continued to test our approach with three other growth rate set points, i.e., $\mu_{\text {set }}=0.05,0.20$, and $0.30 \mathrm{~h}^{-1}$, respectively. The results are shown in Fig. 3. The growth rate during the fed-batch phase was calculated from the first enzyme dosing up the point where the calculated growth rate dropped below a threshold of $\mu_{\exp }=0.05 \mathrm{~h}^{-1}$, indicating the end of
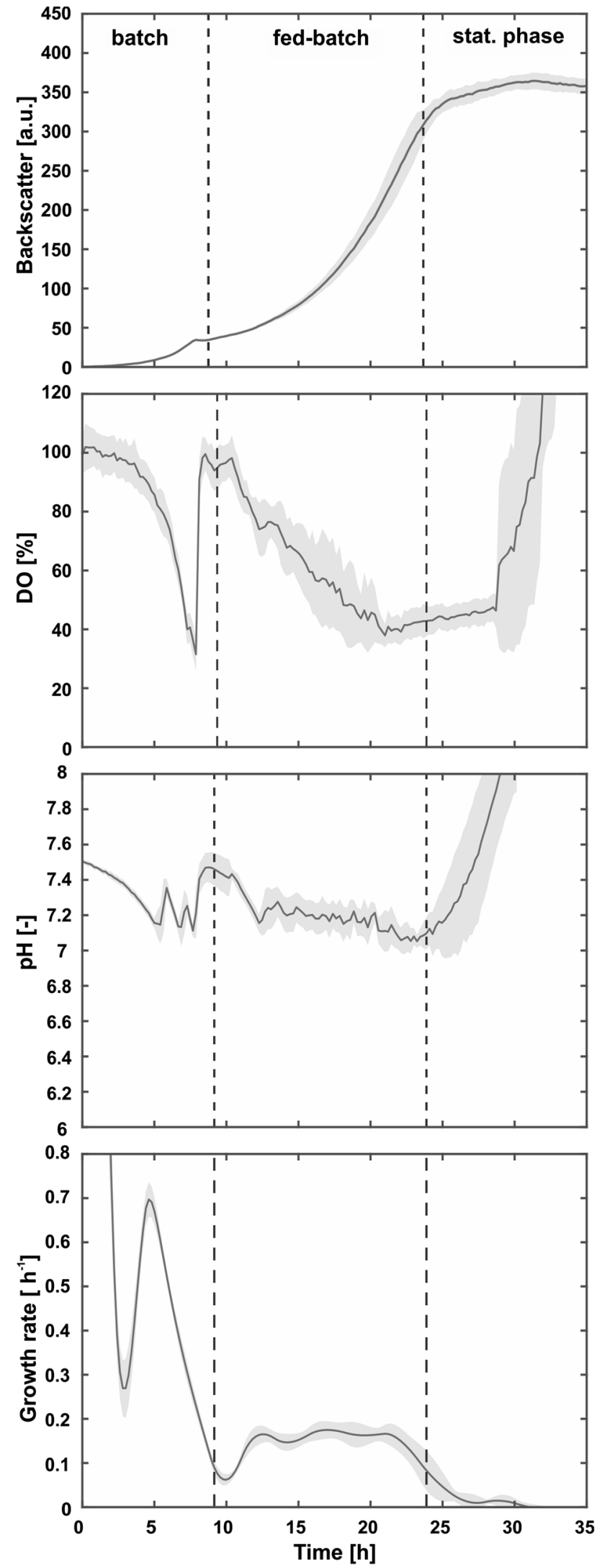

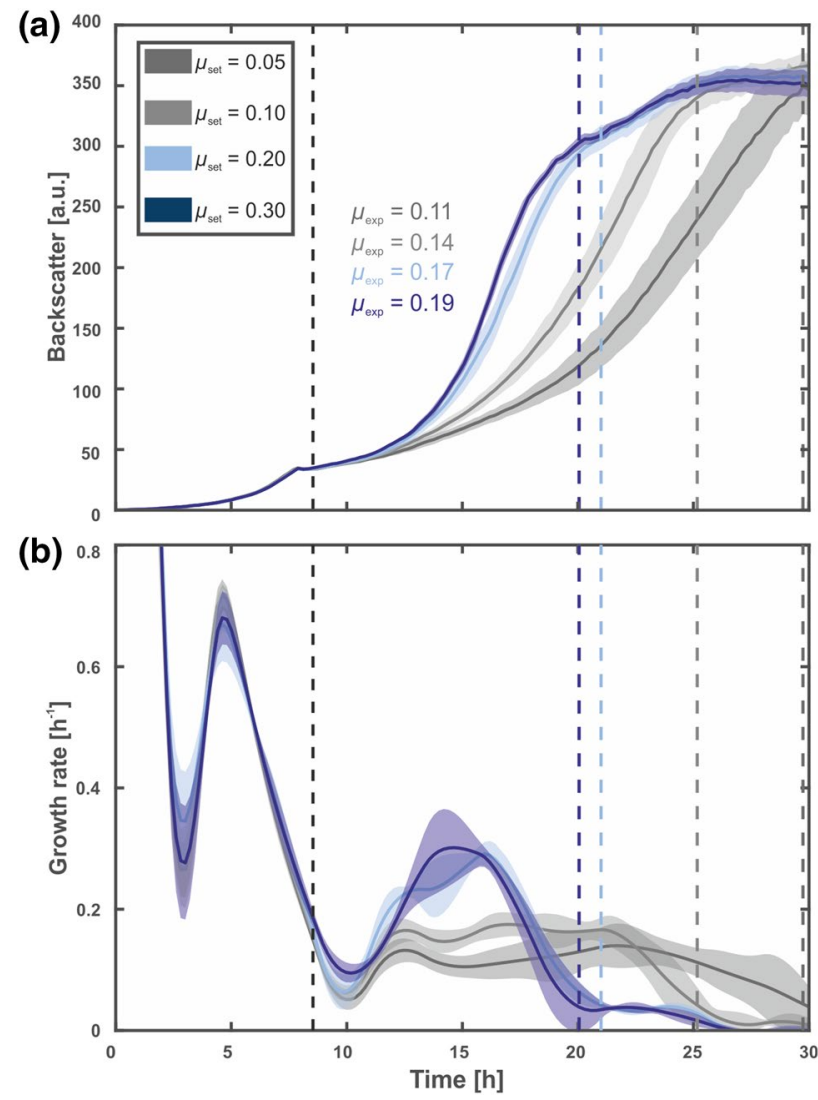

Fig. 3 Exponential fed-batch cultures of C. glutamicum ATCC 13032 with enzyme addition at four different growth rate thresholds. Cultivations were performed in a 48 -well FlowerPlate at $30{ }^{\circ} \mathrm{C}$, $1300 \mathrm{rpm},>85 \%$ humidity, and the initial filling volume was $800 \mu \mathrm{L}$. Modified CGXII medium with $5 \mathrm{~g} \mathrm{~L}^{-1}$ D-glucose, a dextrin equivalent of $75 \mathrm{~g} \mathrm{~L}^{-1}$ D-glucose and $50 \mathrm{mM}$ MOPS were used. The $\mathrm{pH}$ was kept constant at 7.1 through addition of $2.5 \%\left(\mathrm{~m} \mathrm{v}^{-1}\right) \mathrm{NH}_{3}$. Four different growth rate set points $\mu_{\text {set }}=0.05,0.1,0.2$, and $0.3 \mathrm{~h}^{-1}$ were tested. The growth rates were kept above the set points through specific addition of Amyloglucosidase. Dark lines represent the arithmetic means of 12 biological replicates and shaded areas represent the corresponding standard deviations. The cultivations were stopped when a maximal filling volume of $1200 \mu \mathrm{L}$ was reached. a shows the volume corrected backscatter signal and $\mathbf{b}$ shows the growth rate calculated via spline approximation after the experiment. The dotted lines represent the start of the fed-batch and the end point, determined when the growth rate dropped below $0.05 \mathrm{~h}^{-1}$

the fed-batch phase. The lowest set point of $\mu_{\text {set }}=0.05 \mathrm{~h}^{-1}$ consequently resulted in the slowest biomass increase during fed-batch cultivation and the longest fed-batch phase of $20 \mathrm{~h}$. Moreover, the increase in $\mu_{\text {set }}=0.1$ and $0.2 \mathrm{~h}^{-1}$ also resulted in faster biomass accumulation with $\mu_{\exp }=0.14 \mathrm{~h}^{-1}$ and $0.17 \mathrm{~h}^{-1}$, respectively. Strikingly, set points of $\mu_{\text {set }}=0.2$ and 0.3 were yielding very similar experimental growth rates (Fig. 3b).

This experiment demonstrated that a certain range of growth rates can be realized with the developed system. Especially in the beginning of the fed-batch phase and for the two set points $\mu_{\text {set }}=0.05$ and $0.1 \mathrm{~h}^{-1}$, differences in growth can be seen. However, after $10 \mathrm{~h}$ of the fedbatch phase, growth curves start to slightly deviate from exponential trends indicated by the plateau (Fig. 3a). The reason for this effect probably lies in the applied dosing regime: only the actual biomass was considered when calculating the amount of enzyme to be added for cleaving the dextrin polymer. Therefore, by additionally taking the growth rate set point into account would possibly solve this issue, since a higher amount of enzyme could be added when aiming for higher exponential growth rates during fed-batch operation.

Another challenge is presented by the set point of $\mu_{\text {set }}=0.3 \mathrm{~h}^{-1}$ : although the system added more enzyme under these conditions, the growth rate could not be increased accordingly. A possible explanation could be that all open sites of the glucose polymer were already occupied by enzyme and consequently, the D-glucose release rate reached its maximum. A possible solution might be the addition of further highly concentrated dextrin, allowing for more open enzyme sites.

To demonstrate the broad applicability of our approach, fed-batch cultivations with $E$. coli and $P$. pastoris were conducted with $\mu_{\text {set }}=0.1 \mathrm{~h}^{-1}$ as the applied threshold. The organisms were cultivated in chemically defined media with $5 \mathrm{~g} \mathrm{~L}^{-1}$ D-glucose for an initial batch phase and $35 \mathrm{~g} \mathrm{~L}^{-1}$ dextrin for the subsequent fed-batch phase (Fig. 4 and S4).

Since both microorganisms represent different morphologies, the absolute values of backscatter signals varied greatly. However, both growth curves showed the expected exponential fed-batch profile. While the initial batch phase with consumption of free $\mathrm{D}-$ glucose took $12 \mathrm{~h}$ for P. pasto$r i s$, it was 3 h longer for E. coli. In both cases, the end of the batch phase was marked by a sudden increase in the DO signal. Interestingly, for $E$. coli, a second spike after $17 \mathrm{~h}$ occurred, which was most likely due to the consumption of overflow metabolites such as acetate.

The duration of the subsequent fed-batch phases was also different for both organisms, i.e., $15 \mathrm{~h}$ for $P$. pastoris and $12 \mathrm{~h}$ for $E$. coli, respectively. The resulting growth rate of $\mu_{\text {exp }}=0.11 \pm 0.03 \mathrm{~h}^{-1}$ for $P$. pastoris matched almost perfectly with the set point growth rate. For $E$. coli; however, the experimentally observed growth rate was significantly higher $\left(\mu_{\exp }=0.17 \pm 0.07 \mathrm{~h}^{-1}\right)$. This finding can be explained by the overflow metabolism in the batch phase, which led to a false detection of the end of this phase, i.e., before all metabolites were consumed. As a direct consequence, the first Amyloglucosidase pulse was given too early, leading to a release of $\mathrm{D}$-glucose amount above the level that is required to limit the growth rate at the defined set point.

Nevertheless, both experiments have demonstrated the general applicability of our technology to industrial relevant microorganisms. 

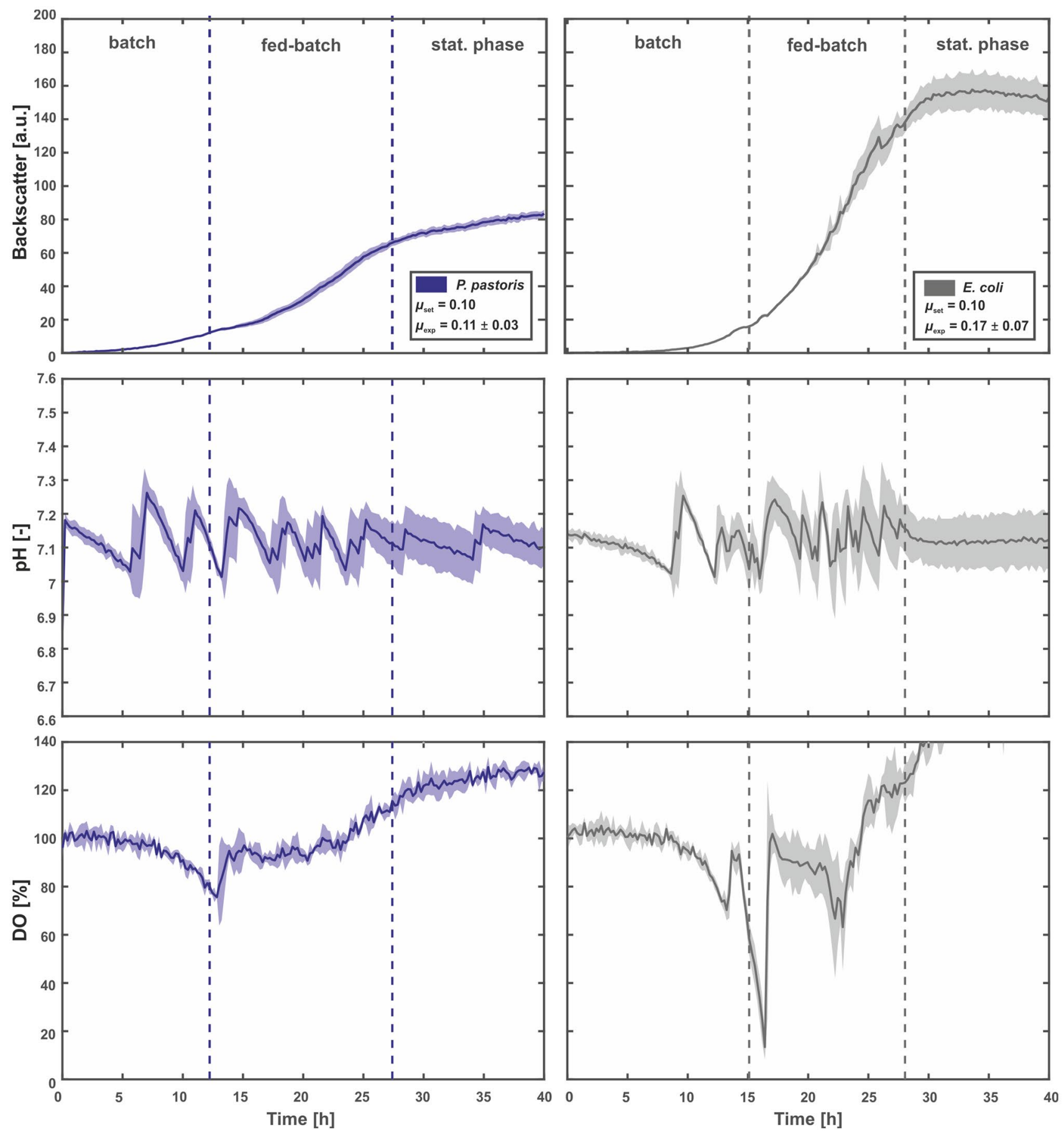

Fig. 4 Fed-batch cultivation of E. coli and P. pastoris wild-type strains utilizing the FeedER technology. Cultivations were performed in a 48-well FlowerPlate at $30{ }^{\circ} \mathrm{C}, 1300 \mathrm{rpm},>85 \%$ humidity, and the initial filling volume was $800 \mu \mathrm{L}$. Modified defined media with $5 \mathrm{gL}^{-1} \mathrm{D}$-glucose, a dextrin equivalent of $35 \mathrm{~g} \mathrm{~L}^{-1} \mathrm{D}$-glucose, and $50 \mathrm{mM}$ MOPS were used. The $\mathrm{pH}$ was kept constant at 7.1 through addition of $2.5 \%\left(\mathrm{~m} \mathrm{v}^{-1}\right) \mathrm{NH}_{3}$. The growth rate was kept above the set point through specific addition of Amyloglucosidase. Dark lines represent the arithmetic means of 12 biological replicates and shaded areas represent the corresponding standard deviations (color figure online) 


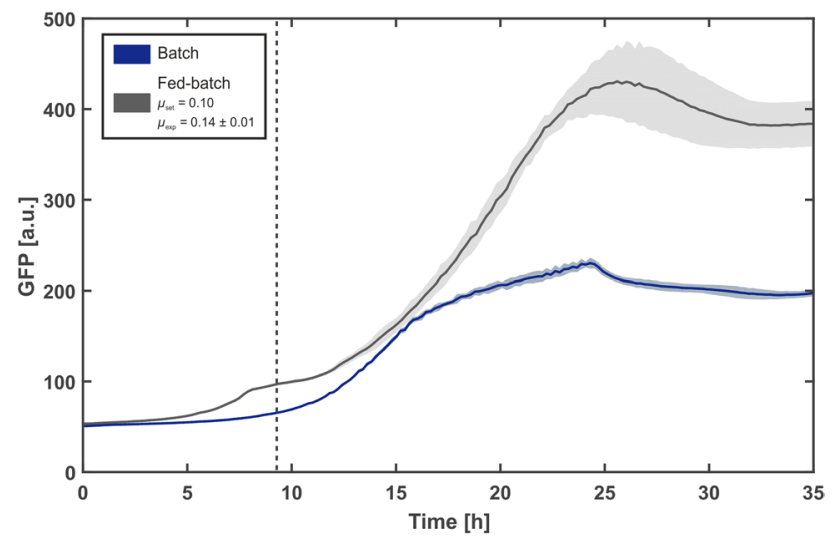

Fig. 5 GFP production with C. glutamicum pCGPhoD ${ }^{\mathrm{Cg}}-\mathrm{GFP}$ in microtiter plate cultivations. Cultivations were performed in a 48-well FlowerPlate at $30{ }^{\circ} \mathrm{C}, 1300 \mathrm{rpm},>85 \%$ humidity and the initial filling volume was $800 \mu \mathrm{L}$. The batch was performed in standard CGXII with $80 \mathrm{~g} \mathrm{~L}^{-1}$ D-glucose. Modified CGXII medium with $5 \mathrm{~g} \mathrm{~L}^{-1}$ D-glucose, a dextrin equivalent of $75 \mathrm{~g} \mathrm{~L}^{-1}$ D-glucose and $50 \mathrm{mM}$ MOPS was used for the fed-batch cultivation. Here the $\mathrm{pH}$ was kept constant at 7.1 through addition of $2.5 \%\left(\mathrm{~m} \mathrm{v}^{-1}\right) \mathrm{NH}_{3}$. The growth rate was kept above the set point $\mu_{\text {set }}=0.1$ through specific addition of Amyloglucosidase. Dark lines represent the arithmetic means of 12 biological replicates and shaded areas represent the corresponding standard deviations. The secreted GFP production for both batch and fed-batch cultivations were analyzed via fluorescence measurement performed by the BioLector

\section{Application of FeedER for studying protein production}

In a comparative application study, the strain $C$. glutamicum pCGPhoD ${ }^{\mathrm{Cg}}$-GFP that is capable of expressing and secreting the model protein GFP was cultivated in both batch and fed-batch conditions. GFP secretion was enabled by Tat translocation using PhoD as Tat-specific signal peptide and its extracellular accumulation was monitored online via fluorescence measurement within the BioLector. The same total amount of D-glucose $\left(80 \mathrm{~g} \mathrm{~L}^{-1}\right)$ was applied for both cultivations and the $\mathrm{pH}$ was controlled in an automated manner as described above. For the fed-batch cultures, four different growth rate thresholds for the feedback-regulated process control were set, i.e., $\mu_{\text {set }}=0.05,0.1,0.2$, and $0.3 \mathrm{~h}^{-1}$, respectively.

Figure 5 shows the GFP production in the batch cultivation and an exemplary fed-batch cultivation $\left(\mu_{\text {set }}=0.1 \mathrm{~h}^{-1}\right)$. Data from other cultivations are shown in Fig. S2. Within the batch cultivation, a maximum in GFP titer (216 \pm 6 a. u.) was reached after $25 \mathrm{~h}$. In comparison, within the fed-batch cultivation, the amount of secreted GFP was almost doubled $(417 \pm 76$ a. u) at equal cultivation time.

Total GFP titer and substrate-specific product yields were calculated for all cultivations (Fig. 6). Starting from the highest titer and yield (417 and $Y_{\mathrm{P} / \mathrm{X}}=1.15$, respectively)
Fig. 6 Total GFP titer (a) and biomass-specific (b) product yield of fed-batch and batch cultivations. Cultivations were performed in a 48-well FlowerPlate at $30{ }^{\circ} \mathrm{C}, 1300 \mathrm{rpm},>85 \%$ humidity, and the initial filling volume was $800 \mu \mathrm{L}$. In all experiments, a total of $80 \mathrm{~g}$ $\mathrm{L}^{-1} \mathrm{D}$-glucose was provided. Biomass specific GFP yield was calculated utilizing the online backscatter and GFP fluorescence signals at the end of the cultivation. Whiskers extend to quartile 1 and quartile 3 , respectively. Diamonds mark outliers in the dataset. A point is considered an outlier if its value is higher than $\mathrm{Q} 3 * 1.5 * \mathrm{IQR}$ (interquartile range) for points higher than the median or lower than $\mathrm{Q} 1 * 1.5 * \mathrm{IQR}$ for points lower than the median value
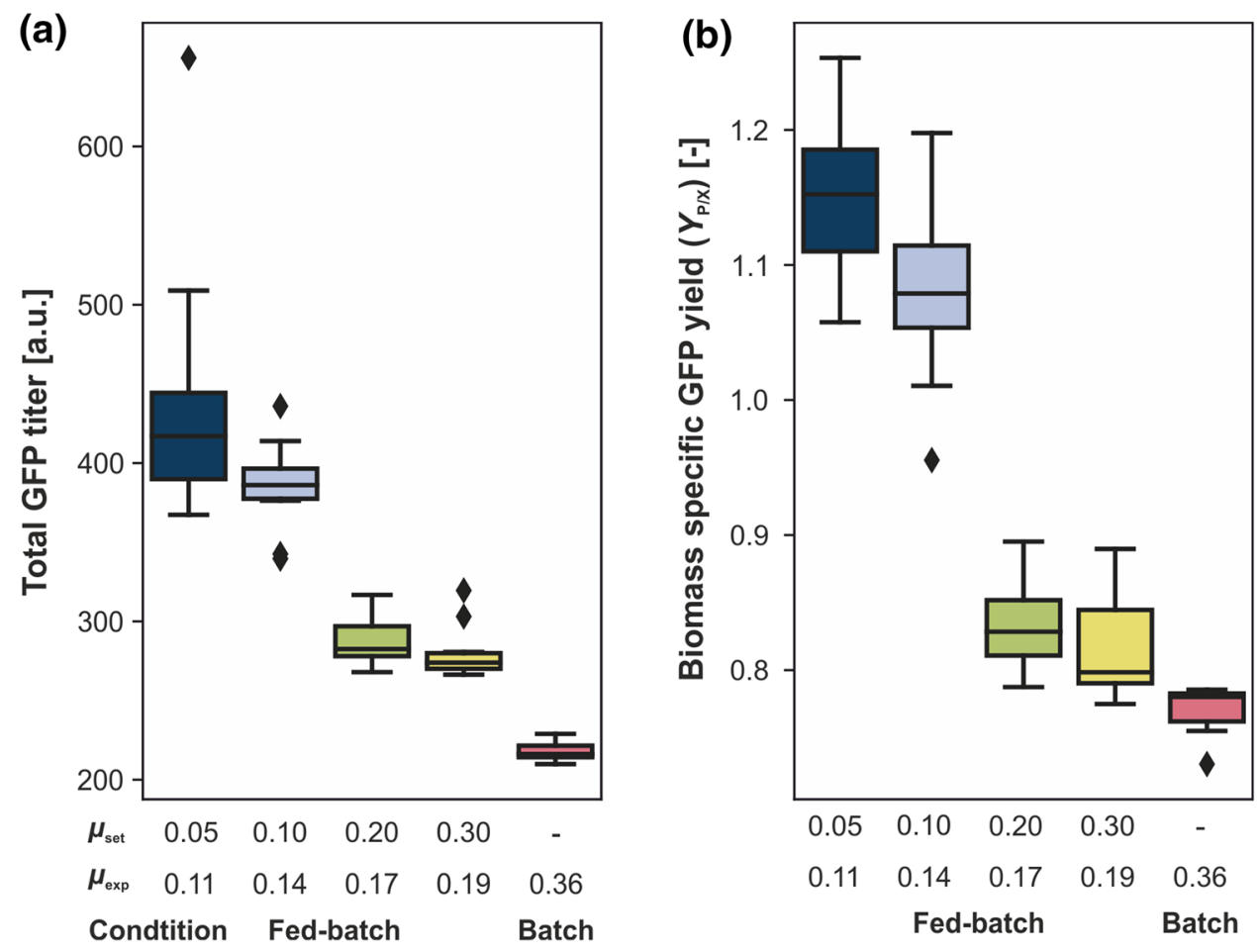
at the lowest growth rate $\left(\mu_{\exp }=0.11 \mathrm{~h}^{-1}\right)$, both quantities continuously decreased with increasing growth rates leading to a final reduction of $34 \%$ and $31 \%$ at the highest rate $\left(\mu_{\exp }=0.19 \mathrm{~h}^{-1}\right)$. This can be explained by the fact that with increasing substrate availability, GFP production is not increased at the same rate as compared to biomass growth. Consequently, the specific product yield dropped. Since the average growth rate of the batch cultivation was the highest, GFP titer and yield were also the lowest. Overall, a lower growth rate during fed-batch cultivation proved to be highly beneficial for GFP production. This correlation has already been reported in the literature for the intracellular production of proteins, such as GFP or nucleases, with E. coli [28, 29]. More recently, the same observation was made for the secretion of cutinase with $C$. glutamicum in a bioreactor fedbatch process [30].

\section{Conclusion}

In this study, we demonstrated the development of FeedER, which is a feedback-controlled slow-release fed-batch system. FeedER is based on automated $\mathrm{pH}$ control and addition of Amyloglucosidase, which in turn controls the substrate release rate to realize defined exponential growth during feed phase. By employing this system, fed-batch bioprocesses can be screened at high-throughput and with minimal manual effort. Therefore, our approach can significantly accelerate the scale-up of bioprocesses from lab scale to industrial scale.

Future work will focus on tackling the presented challenges of the current system. In particular, by employing the developed techniques, different feeding modes, e.g., constant feed rates or different slow-release systems can be realized. The feedback could then be used to account for enzyme instability or changing environmental conditions, which are the common drawbacks for enzyme-based slow-release systems. Furthermore, combining FeedER with already-established phenotyping technologies such as repeated low-volume sampling [31] or proteomics [32] will lead to deep insights regarding the metabolism of potential producer strains at an early process stage. Another interesting extension would be the combination with automated adaptive laboratory evolution techniques [27], where untargeted strain development could be realized under carbonlimiting conditions.

\footnotetext{
Acknowledgements Funding was received from the Enabling Spaces Program "Helmholtz Innovation Labs" of the German Helmholtz Association to support the "Microbial Bioprocess Lab-A Helmholtz Innovation Lab". Further funding was received by the Bioeconomy Science Center (BioSC, Grant. No. 325-40000213) as part of the Focus FUND project "HyImPAct - Hybrid processes for important precursor and active pharmaceutical ingredients".
}

\section{Compliance with ethical standards}

Conflict of interest The authors declare that they have no conflict of interests. Furthermore, the authors declare that this study does not include research involving animals or human participants.

Open Access This article is distributed under the terms of the Creative Commons Attribution 4.0 International License (http://creativeco mmons.org/licenses/by/4.0/), which permits unrestricted use, distribution, and reproduction in any medium, provided you give appropriate credit to the original author(s) and the source, provide a link to the Creative Commons license, and indicate if changes were made.

\section{References}

1. Zheng X, Xing X-H, Zhang C (2017) Targeted mutagenesis: a sniper-like diversity generator in microbial engineering. Synth Syst Biotechnol 2:75-86. https://doi.org/10.1016/j.synbi o.2017.07.001

2. Nødvig CS, Nielsen JB, Kogle ME, Mortensen UH (2015) A CRISPR-Cas9 system for genetic engineering of filamentous fungi. PLoS ONE 10:1-18. https://doi.org/10.1371/journ al.pone. 0133085

3. Shivange AV, Marienhagen J, Mundhada $\mathrm{H}$ et al (2009) Advances in generating functional diversity for directed protein evolution. Curr Opin Chem Biol 13:19-25. https://doi. org/10.1016/j.cbpa.2009.01.019

4. Long Q, Liu X, Yang Y et al (2014) The development and application of high throughput cultivation technology in bioprocess development. J Biotechnol 192:323-338. https://doi. org/10.1016/j.jbiotec.2014.03.028

5. Hemmerich J, Noack S, Wiechert W, Oldiges M (2018) Microbioreactor systems for accelerated bioprocess development. Biotechnol J 13:1700141. https://doi.org/10.1002/biot.201700141

6. Betts JI, Baganz F (2006) Miniature bioreactors: current practices and future opportunities. Microb Cell Fact 5:21. https:// doi.org/10.1186/1475-2859-5-21

7. Lattermann C, Büchs J (2015) Microscale and miniscale fermentation and screening. Curr Opin Biotechnol 35:1-6. https ://doi.org/10.1016/j.copbio.2014.12.005

8. Scheidle M, Jeude M, Dittrich B et al (2010) High-throughput screening of Hansenula polymorpha clones in the batch compared with the controlled-release fed-batch mode on a small scale. FEMS Yeast Res 10:83-92. https://doi.org/10.11 11/j.1567-1364.2009.00586.x

9. Kensy F, Hemmerich J (2013) BPI2013-09 automation of microbioreactors. BioProcess Int 11(8):68-76

10. Jeude M, Dittrich B, Niederschulte H et al (2006) Fed-batch mode in shake flasks by slow-release technique. Biotechnol Bioeng 95:433-445. https://doi.org/10.1002/bit.21012

11. Wilming A, Bähr C, Kamerke C, Büchs J (2014) Fed-batch operation in special microtiter plates: a new method for screening under production conditions. J Ind Microbiol Biotechnol. https://doi.org/10.1007/s10295-013-1396-x

12. Panula-Perälä J, Šiurkus J, Vasala A et al (2008) Enzyme controlled glucose auto-delivery for high cell density cultivations in microplates and shake flasks. Microb Cell Fact 7:31. https:// doi.org/10.1186/1475-2859-7-31

13. Šiurkus J, Panula-Perälä J, Horn U et al (2010) Novel approach of high cell density recombinant bioprocess development: optimisation and scale-up from microlitre to pilot scales while maintaining the fed-batch cultivation mode of E. coli cultures. Microb Cell Fact 9:35. https://doi.org/10.1186/1475-2859-9-35 
14. Krause M, Neubauer A, Neubauer P (2016) The fed-batch principle for the molecular biology lab: controlled nutrient diets in ready-made media improve production of recombinant proteins in Escherichia coli. Microb Cell Fact 15:110. https://doi. org/10.1186/s12934-016-0513-8

15. Panula-Perälä J, Vasala A, Karhunen J et al (2014) Small-scale slow glucose feed cultivation of Pichia pastoris without repression of AOX1 promoter: towards high throughput cultivations. Bioprocess Biosyst Eng 37:1261-1269. https://doi.org/10.1007/ s00449-013-1098-9

16. Cruz Bournazou MN, Barz T, Nickel DB et al (2017) Online optimal experimental re-design in robotic parallel fed-batch cultivation facilities. Biotechnol Bioeng 114:610-619. https://doi. org/10.1002/bit.26192

17. Funke M, Buchenauer A, Mokwa W et al (2010) Bioprocess control in microscale: scalable fermentations in disposable and user-friendly microfluidic systems. Microb Cell Fact 9:86. https ://doi.org/10.1186/1475-2859-9-86

18. Funke M, Buchenauer A, Schnakenberg U et al (2010) Microfluidic biolector-microfluidic bioprocess control in microtiter plates. Biotechnol Bioeng 107:497-505. https://doi. org/10.1002/bit.22825

19. Blesken C, Olfers T, Grimm A, Frische N (2016) The microfluidic bioreactor for a new era of bioprocess development. Eng Life Sci 16:190-193

20. Elmahdi I, Baganz F, Dixon K et al (2003) pH control in microwell fermentations of S. erythraea CA340: influence on biomass growth kinetics and erythromycin biosynthesis. Biochem Eng J 16:299-310. https://doi.org/10.1016/S1369-703X(03)00073-1

21. Meissner D, Vollstedt A, van Dijl JM, Freudl R (2007) Comparative analysis of twin-arginine (Tat)-dependent protein secretion of a heterologous model protein (GFP) in three different Grampositive bacteria. Appl Microbiol Biotechnol 76:633-642. https ://doi.org/10.1007/s00253-007-0934-8

22. Keilhauer C, Eggeling L, Sahm H (1993) Isoleucine synthesis in Corynebacterium glutamicum-Molecular analysis of the IlvbIlvn-Ilvc operon. J Bacteriol 175:5595-5603

23. Scheidle M, Dittrich B, Klinger J et al (2011) Controlling pH in shake flasks using polymer-based controlled-release discs with pre-determined release kinetics. BMC Biotechnol 11:25. https:// doi.org/10.1186/1472-6750-11-25

24. Ghosalkar A, Sahai V, Srivastava A (2008) Optimization of chemically defined medium for recombinant Pichia pastoris for biomass production. Bioresour Technol 99:7906-7910. https:// doi.org/10.1016/j.biortech.2008.01.059

25. Funke M, Diederichs S, Kensy F et al (2009) The baffled microtiter plate: increased oxygen transfer and improved online monitoring in small scale fermentations. Biotechnol Bioeng 103:1118 1128. https://doi.org/10.1002/bit.22341

26. Toeroek C, Cserjan-Puschmann M, Bayer K, Striedner G (2015) Fed-batch like cultivation in a micro-bioreactor: screening conditions relevant for Escherichia coli based production processes. Springerplus 4:490. https://doi.org/10.1186/s40064-015-1313-z

27. Radek A, Tenhaef N, Müller MF et al (2017) Miniaturized and automated adaptive laboratory evolution: evolving Corynebacterium glutamicum towards an improved d-xylose utilization. Bioresour Technol 245:1377-1385. https://doi.org/10.1016/j.biort ech.2017.05.055

28. Cheng L-C, Hor L-I, Wu J-Y, Chen T-L (2003) Effect of specific growth rate on the production of a recombinant nuclease by Escherichia coli. Biochem Eng J 14:101-107. https://doi. org/10.1016/S1369-703X(02)00156-0

29. Bienick MS, Young KW, Klesmith JR et al (2014) The interrelationship between promoter strength, gene expression, and growth rate. PLoS ONE 9:e109105. https://doi.org/10.1371/journ al.pone. 0109105

30. Hemmerich J, Moch M, Jurischka S et al (2018) Combinatorial impact of Sec signal peptides from Bacillus subtilis and bioprocess conditions on heterologous cutinase secretion by Corynebacterium glutamicum. Biotechnol Bioeng. https://doi. org/10.1002/bit.26873

31. Hemmerich J, Tenhaef N, Steffens C et al (2018) Less sacrifice, more insight: repeated low-volume sampling of microbioreactor cultivations enables accelerated deep phenotyping of microbial strain libraries. Biotechnol J 1800428:1-10. https://doi. org/10.1002/biot.201800428

32. Voges R, Noack S (2012) Quantification of proteome dynamics in Corynebacterium glutamicum by $15 \mathrm{~N}$-labeling and selected reaction monitoring. J Proteom 75:2660-2669. https://doi. org/10.1016/j.jprot.2012.03.020

Publisher's Note Springer Nature remains neutral with regard to jurisdictional claims in published maps and institutional affiliations. 